\title{
A response to the critics
}

\author{
Ian Kennedy Faculty of Laws, King's College, London
}

My first inclination (and indeed my second and third) was to decline the Editor's invitation to respond to these various comments on the Reith Lectures. After all, I have had my say and it is only right that others should have theirs. Equally it is inevitable that some will disagree with some or all of what I say. Indeed, I have resisted all other invitations to respond to critics at any length, although the temptation has been great. For, it is only fair to say that the lectures have not met with great critical acclaim, at least from those who regard themselves as spokesmen for what may be loosely described as the medical establishment. The book of the lectures (I) which I wrote contemporaneously as an expanded version of them has tempted this same class of critics to write some of the worst and most bitter reviews I have seen.

In the event, I have decided to break the golden rule of 'never reply'. One reason for doing so is that this is a scholarly journal the terms of reference of which include the promotion of the study of contemporary medico-moral problems. My hope is that my response may contribute to this promotion of study.

Before responding to each critic in turn, I will offer a few general comments by way of introduction.

I) I was not surprised by the adverse criticism my views have received from some, particularly doctors who identify themselves, for whatever reason, with the existing status quo as to how medicine and health care is perceived and organised. I was, however, taken aback somewhat by the vehemence of the attacks (see, eg the review of my book in the Times Literary Supplement (2)). It is for others to wonder why so much energy has been expended in demolishing what, according to the various writers, was already patently absurd, untenable, clearly unoriginal and riddled with inaccuracies and/or, misperceptions.

2) It is interesting to contrast these published reactions (admittedly not all of which have been hostile) with the views expressed to me both in the huge amount of correspondence $I$ have received since the lectures (and continue to receive) and privately at meetings and lectures up and down the country. These latter views have been overwhelmingly encouraging and approbatory. They have come from both doctors and non-doctors and this latter category has comprised not only liberal chic
Guardian-reading herbivores, but also people draw from all strata of society. I make this point merety to record it publicly, not out of any sense of selfes justification.

3) It is important to be aware of the form the Rei Lectures take. They are lectures intended for large audience (in all close to a million in the UR and many more in other parts of the world, fro India to New Zealand to Canada). The only cono mon denominator of the audience is an intellectually acquisitive appetite and the ability to listen without interruption for just less than half an hour. The is no room for jargon, for scholarly footnotes of references, or on occasions for the pursuit of a idea which, though interesting, could lose of confuse the listener with whom the only link is this fragile one of the spoken word. At the same time the lectures must be in such a form that precisely the same text used in the broadcast is fit for publicas tion. It is a wonderfully exciting challenge to wort within such constraints and yet aim to explorfe difficult and important themes and one I particularis enjoyed.

4) One of the consequences of the form of the lectures is that great care must be taken to use language with a maximum of economy but wit great clarity and precision. My background as lawyer reinforces this concern for saying what on intends to say. The assumption is, of course, that others will then concentrate their attention on whate. one said, on the words used, that they will not sub@ stitute other words carrying different nuances that they will not see implications which are nop implied, that they will not wrest words and argu ments out of their context. It was perhaps naive of me to expect those who would comment on the lectures to do me this particular favour. It has certainly been one of the most galling experiences to witness how many commentators simply have not done so. I have often wondered whether anothero set of Reith Lectures was produced and circulated in which I actually do express views and arguments๊ later attributed to me. It becomes tedious, it even? sounds rather weak, to have to insist constantlyo that 'I did not say that'. Yet this is so often the case, and many of the criticisms in this journal provideo good examples.

5) Several common features have emerged in theo critical reviews of the lectures. First, and perhaps most important, editors whether of newspaperso 
or journals, have almost without exception commissioned their reviews from doctors. The Editor of this journal continues the pattern. Of the nine papers six are written by doctors and one by a medical student. Of the two others, one is a philosopher from Florida whose acquaintance with conditions in the UK is not stated nor, as I shall suggest, immediately obvious. My lectures were about the institution of medicine. They touched on, for example, the notion of health, the politics of health care, the ethics of medical practice, the sociology and philosophy of medicine. Doctors are not necessarily the only or the best people to comment on these. Indeed, they may begin with a set of assumptions or biases which could well limit their readiness to consider views outside the ambit of current orthodoxy.

My second point is a consequence of this. Many critics have made the observation that I am a layman, either directly, or indirectly by referring to the fact that I am a lawyer. Now, the word layman and the notion behind it need to be watched very carefully. It is a word all of us professionals use to define out of competence those who are not members of our profession yet would presume to comment on what we do. When it comes to the sociology or the politics of medicine and health care, the analysis of medical ethics, the role of law or of consumerism in medicine, or the nature and use of language, I am no more a layman than the doctor, indeed often less so since I have spent more than a decade studying these very things. Yet, if it is largely doctors who are invited to comment and therefore to be heard to the exclusion of others, credibility is given to the idea that medical expertise is a necessary prerequisite for comment. This invites the conclusion that ex hypothesi, my views not being the views of a doctor, suffer from a crippling disadvantage.

The third common feature of criticisms is that all (or nearly all) of what I said has been heard before. It is, as Wilkes puts it, 'warmed-up Illich', thereby getting two shots for the price of one, for not only am I condemned for unoriginality but I am also neatly bracketed with the loonier fringe last seen leaving Cuernavaca. Clare repeats the charge in an interesting way since he also wants two bites of the cherry. To Clare not only has what I said been said by doctors for years, but on examination it also proves to be pretty poor stuff. I still intend to talk to Clare but I am not sure whether his fellow doctors will forgive him! I have sought to reply to the charge of lack of originality in the preface of my book and am pleased to see that Black in his comments specifically responds to it.

The last feature I would draw attention to is the extent to which critics who would attack have resorted to what I would call argument by dismissal or by epithet rather than by reasoned refutation.
In his editorial of March I98I, the Editor of this journal showed the way. He wrote that, 'it is almost as though he [Kennedy] assumes that the sole purpose of those who practice medicine is to maximise happiness . . . Note the word 'almost'. This conveys both the admission that I made no such assumption, while allowing the reader to conclude that I in fact did! It further allows the Editor a two-pronged attack. He condemns such an assumption (which, you will recall, he conceded I did not make). And in the condemnation, 'the inadequacy of such hedonistic utilitarianism hardly needs stating', the Editor can resort both to argument by dismissal and by epithet.

The editorial offers several other examples of these techniques. My 'combative style' was, the Editor suggests 'designed no doubt to achieve the publicity which was in fact achieved'. A slightly discreditable motive is neatly suggested by resort to epithet. Again, I exhort my listeners, the Editor writes, to 'become the masters of medicine not its servants'. This prompts the comment from him 'hardly a relationship of autonomous equals that!'. Missing in this destructive aside is any appreciation of the fact that medicine is not the same as the medical profession and that my argument was somewhat more subtle. A respectable argument can be made for the view that the institution of medicine should reflect the views and values of society at large and that from this may flow in time a different and more equal relationship between doctor and patient. I sought to make this argument but the Editor's aside would dismiss it.

The Editor's conclusion is perhaps the best example of what I have in mind. 'All this aggro', he wrote, 'makes good copy for the popular media but it does not encourage doctors to cooperate in the thoughtful exercises which Kennedy is properly advocating'. 'The popular media' has just the right tone of lofty, somewhat pained, dismissal.

I turn now to consider the criticisms of the various commentators. I have concentrated only on what I regard as important areas of agreement or disagreement. Even so, the result is fairly lengthy, for which I apologise.

\section{Wilkes}

Petulance is not a condition ordinarily regarded as compatible with reasoned argument. Wilkes' offering is no exception. I think I deserved reasoned argument, but there it is. I can start with Wilkes' paper because it is representative of one type of response which has been made to the Reith Lectures. In it are contained almost all of the arguments which I have had to meet, together with an almost perverse refusal to follow my arguments.

ARGUMENT I

It is open to Wilkes to describe my lectures as 
'warmed up Illich'. I gladly pay tribute to Illich and derive much intellectual support from Medical Nemesis (3). But there are numerous differences. For example, though I urge the 'demystification of all medical matters' I do not anywhere talk of an 'iatrogenic pandemic' which is one of Illich's central theses. Nor do I urge, for example, the merit of pain and suffering nor the kind of primitivism and hostility to progress which play a crucial part in Illich's political analysis.

\section{ARGUMENT 2}

We meet a major problem as regards the reception of the lectures. Wilkes protests too much when he says, 'do not blame the doctors'. Wilkes wants to turn me into a doctor-basher and then I can be dismissed. I do not blame doctors. I am not interested in blame. I am interested in the future. Wilkes misses three points which are specifically stated and are very important. First, I was concerned with the institution of medicine, not doctors, though as I argued doctors play a crucial role in shaping the institution. Second, I specifically said that much that must be done was for government and was not for doctors. Third, I specifically stated that the present state of affairs was a consequence of the conduct of all of us. The same response can be made concerning his remarks on developing countries. I do not blame doctors. I point to the way medicine is thought of and some of its consequences. And of course his final call for doctors to be regarded as a dedicated, intelligent and incorruptible profession has never been rejected by me. But this is not really the point.

\section{ARGUMENT 3}

My examples Wilkes alleges are from the United States. In fact very few are. To say that Quinlan is not typical of British medicine is perverse. The problem posed in her case presents itself every day: how to respond to the irretrievably unconscious, whether from accidents or drugs. The fact that the Americans have sought to solve the question in a particular way may be different. As it happens the Court's decision in its discussion of the proper limits to the need to strive to keep alive is in my view excellent. Furthermore, and this is the sad thing when one reads the comments of someone like Wilkes, it is a great help to doctors if only they would understand that it offers a guide to what they need to do where none was present before.

\section{ARGUMENT 4}

The reference to 'malodorous lawyers' (a metaphorical group I imagine) and 'truculent consumerism' betrays two of Wilkes' prejudices. I am a lawyer and am an advocate of consumerism. To coin an Americanism I begin with two strikes against me. But as I have suggested, being a lawyer is not synonymous with being disqualified from commenting on the institution of medicine.

\section{ARGUMENT 5}

The ethical problems I posed should not be decideक्र by the 'ghastly fantasy of some on-call committee'. The fantasy is of Wilkes' making. Nowhere do $\underline{\vec{G}}$ suggest this. I make a distinction between the principles by reference to which decisions are made and the decision-making itself. The principles, $\overline{\bar{T}}$ argue, and am convinced, are for society at large to establish by whatever mechanism is deemed appropriate. Such principles then serve to guide and delimit but not destroy the discretion to be exercised by the professional in making the particular decision. It is so easy to refuse to take this point and make a mockery by referring to 'on-call committees'. It is also very silly.

\section{ARGUMENT 6}

Don't blame doctors says Wilkes for diagnosing illness or prescribing tranquillisers: patients some times want these and what alternatives are there. I did not observe that doctors should not prescribs tranquillisers. I merely observed that they did se And I suggested that this has obvious political an social ramifications. I distinctly left it to the audience to contemplate which course is better; to suffep unhappiness and perceive it in social and politica terms or to take Valium.

\section{ARGUMENT 7}

The WHO notion of health according to Wilke is useless and discredited: doctors are more interested in the maintenance of independence. Again Wilkes does not take my point. Leave asid $\vec{\epsilon}$ the acceptance of the WHO goal by the Roya College of General Practitioners, it was precisel my point that doctors cannot achieve this goal since health is not so much a product of medical cares as of political and social circumstances and must be seen as such.

\section{ARGUMENT 8}

An office in King's College is not a good base for checking on vocational training schemes. The suggestion of the Ivory Tower is there. But most off us are aware of vocational training schemes. Indeec, I have lectured on some and escaped unscathedi Wilkes seeks to persuade me that things are changing 'transforming basic professional attitudes at gre speed'. My impression, for what it is worth, is tháe the change is less pronounced and less rapid. The relatively recent research by Cartwright and Andefe son (4) tends to bear this out. And why I may ask i passing would Wilkes want me to be aware that change is rapidly on the way? Much of Wilkes offering would tend to suggest change was not greatly needed.

\section{ARGUMENT 9}

Preventive medicine is a good thing but does not work. The example cited is of the ordinary 
unskilled Glaswegian who is given more money and will buy more fags and booze. Is Wilkes saying that it is hopeless? If not then surely it is incumbent, as I argued, on all of us to do better, and there are many ways of doing so which are waiting to be explored if the will were there and the lobbies were resisted.

\section{Black}

I welcome Black's considered reflections. It is inevitable that there must be disagreements, though some of them may flow from a misperception of my arguments. Black like others is exercised by my concentration on the notion of power, particularly in the context of the concept of illness, saying that it is something which, if it exists at all, has been thrust upon doctors. He says there is no conscious conspiracy to deprive patients of their rights. I, of course, specifically deny that there is such a conspiracy. One difficulty medical commentators have had is that the word power has been interpreted as if it carried an evaluative connotation, as if power was something bad. It is not. It is merely a reality and in the context of professionals it is an inevitability. I drew attention to this reality of power and the implications it carries. I suggested it should be shared with the patient.

I do not reject recourse to a taxonomy of diseases. Again I state that it is here to stay. What I point to are the consequences which may flow from it, particularly the possibility of making taxonomy the end rather than the beginning of care. Though I concede the dilemma Black points to concerning the balance between concern for the patient and the illness, I am not persuaded it need be as inevitable as he seems to imply. Surely Black begs the question when he talks of becoming involved with the patient as, getting in the way of the 'full development of skills ... long and patiently acquired'. Which skills does Black have in mind? Surely not those concerned with treating the patient. Equally when he says that if the doctor maintains 'a rigid professional detachment' so and so will follow, this suggests that detachment is part of being a professional doctor. Yet this is precisely the point at issue.

I understand Black's comments on scientific medicine and prevention. I repeatedly said it was a matter of balance and would concede that his experience and wisdom are far greater than mine on where the right balance should be struck. I am not a therapeutic nihilist who wants an end to acute care. Indeed I referred to its continued and inevitable importance. Black credits me with not speaking about prevention and cure in antithetical terms and then subsequently accuses me of doing so. I do not have the naive view that with proper policies illness will vanish. I do insist, however, that it is right to examine where we have struck the balance between prevention and interventionist medicine, that certain political and social changes could obviate a significant proportion of what we call illnesses and that this is preferable to waiting for them to arise and then responding. Black's Report on Inequalities in health (5) is proof that he holds the same views.

Let me explain why I argued that the Health Service has failed us. As Black knows I am a passionate believer in the NHS. The idea I sought to convey is that it has failed us in that first, we, all of us, as a political community have not made it follow the direction it should have taken. Second, we have by its creation, allowed concern for health to be compartmentalised into the Ministry of Health and in turn to become a concern for illness. I would be the first to point to its successes but I feel they do not outweigh what I saw as its and our failures, particularly the maladministration of resources, the concentration on illness with no sustained emphasis on health and the relative underemphasis on prevention. I suspect, in this sense, Black would largely agree with me.

I would take issue with one of Black's interesting comments on McKenzie's work. I do not feel that consumerism should necessarily be regarded as a 'conflict model'. I would suggest that consumerism accepts the functional model of the professional but seeks to define the function differently; that the doctor's role be that of a sharing partner in a joint enterprise as opposed to a paternalistic decision maker. It may be that one method of achieving this is occasional conflict but not all consumerism is conflict: much (and the more successful form) is negotiation and agreement.

On the issue of accountability Black and I must simply differ. He favours self-regulation and seems unwilling to accept that there is a sense of disquiet about it as a notion among non-professionals. His view is complacent but my view is that complacency is uncalled for, a view endorsed by the Royal Commission on the NHS.

Black's final paragraph is most important. He would draw a contrast between my view of the doctor as the servant of society and his view that the doctor is a trained professional responding to the needs of patients. But the two are not necessarily distinct. A doctor may serve his patient's needs while reflecting the views and values of society: indeed he does so now and must do so more and more. Resting on the Hippocratic tradition, as if this is the only view and cannot be changed, is either short-sighted or self-seeking in that it continues the status quo in which the doctor can claim to ignore the interests of society at large when it suits his purpose.

\section{Ackroyd}

I would accept Ackroyd's observation that consumerism in the context of the supply of goods is 
less of a force than it was. One reason may be that the issues now being fought over are less clearcut once the major battles have been won. But I do not think she is right to extend this development to consumerism involving the supply of services. In this latter context it is still in my view a vital force and will remain so until certain points have been gained. Witness if you will the Royal Commission on Legal Services which reported in 1980, whose terms of reference spoke specifically of the service supplied and the consumer.

I would agree, also, that consumers are concerned with more than compensation or discipline. I sought to suggest this in my references to the concern for partnership, communication, consent and the proper disposition of complaints.

In other respects Ackroyd and I are at one. I find particularly interesting her suggestion of a professional inspectorate. I floated this idea myself in a recent $\mathrm{BBC}$ Radio documentary (6) as being worth considering for all professions, but the response was at best lukewarm.

\section{Little}

I welcome Little's observations. I am particularly attracted by the distinction Little draws between ethical competence and technical competence and the need to ensure proper accountability as regards both. It is a distinction I drew myself in my BBC documentary previously mentioned (6). If a profession by definition exists to serve the public in the public interest, then clearly it must ultimately be the public who judge what that interest is and whether it is being served. All professions, medicine included, have traditionally not only claimed to act in the public interest but also to have the unique competence to define that interest. I agree with Little that where ethics or etiquette are concerned the public must have a say in drawing up the principles and ensuring that they are observed and that where the exercise of skill is concerned again there is room for the observations and judgments of the non-professional. I share his final observation tinged as it is with poignancy, if not desperation, that we have always known this but 'all too often we do not act as if we knew it.'

\section{Toon}

Toon is largely concerned with the work of Scadding, Campbell and Roberts. Reference to my comments on the concept of disease is at best tangential. As an addition to the literature on this topic, however, it may be of general interest. In particular the attempt to separate fact from norm identifies an important problem, even if the result is not entirely persuasive. Among the occasional references to my arguments I am unpersuaded by his comments. He does not disprove my argument that the patient is the claimant to the status ill by pointing out that 'the vast majority of medical consultations are initiated not by the doctor but by the patient'. This: indeed is a point I emphasised, but it does not meam that because the patient is the claimant, his claing will be satisfied. My view is that we can validly speak of being ill 'properly-so-called'; that 'il|p' has become a technical term to be used properl 1 only by those with technical expertise, namely doctors. It may also be used in common parlance of course, but here it is used loosely and does no? carry the connotation of being 'really' ill unless an until it is used by the doctor.

At another point I am made to suggest that wha is considered a medical problem is arbitrary. I and not sure what Toon's proposition means. I did not use such words as 'medical problem'. But in anj event I do not recall talking of arbitrariness. I an at pains to point out that the decision, for example whether someone was ill was based on certain reasoned judgments, but judgments that toof account of social circumstances and prevailin 8 norms. As regards the concept of disease I merely pointed to the dangers implicit in the unthinking use of it. I specifically conceded that it was a ternif that must be used, but with care, aware of itgo implications for how we perceive medical care and health generally.

\section{Thomas}

Thomas opens with the usual vigour of a BM spokesman. As with others the concept of power $\sqrt{\overline{8}}$ first to be criticised. For him my views imply tha doctors have aggregated power to themselves as pat of a plan of aggrandisment. This is where I wonder again whether there is another set of Reith Lectures which have been circulated in my name to the BMAP. I specifically rejected any conspiracy by doctors both in the first and last lecture. I merely identifie, what I regard as a social phenomenon, the powe? of the doctor, akin to the power held by aff professionals. I am concerned that the ability of clients to affect their relationship with professionat advisers including doctors is directly related to the. power which the professional is able to asserf asserts, and is allowed to assert. If the desired end is a relationship of mutual responsibility, powf cannot, and should not, rest with the professiona alone.

I am happy to agree with Thomas's descriptiof of the growth of medical ethical dilemmas and the need to foster public participation in their resolution. I think, however, Thomas is a little disingenuous in saying that when difficult issues are identifie $\$$ the public refuses to act. I feel this ignores two points. First, as Thomas knows full well there is continuing resistance on the part of the medice profession as a whole to the proposition that medical ethical issues are properly a subject for publise 
debate. Second, as Thomas again well knows, there is a reluctance among doctors to concede that when an issue does emerge for debate people other than doctors have views of any real value. The device of describing non-doctor commentators as laymen, thereby perfunctorily defining them out of the group of the competent is commonly used even though in matters of ethical analysis it may be the doctor who is the layman. Equally the argument is used that clinical experience is an essential prerequisite to being entitled to comment, a claim which achieves the same result as the layman argument. Third, it is fair to say political decisions are being taken by the public through various institutional mechanisms ; to take Thomas's example, heart transplants were not funded by the DHSS for a number of years as a matter of political decision, no smoking areas are slowly spreading, and the wearing of seat belts will soon be compulsory. The process is slow but so it should be if considered decisions are to be taken.

Thomas goes on to identify what he sees as problems of public involvement and cites the doctor who 'honestly believes that he cannot work within the constraints laid down by the public'. Here we meet again the notion of the doctor being somehow separate from society and in certain circumstances possessed of greater moral wisdom or insight such that he may entertain ignoring the constraints laid down by society. If we contemplate that such a constraint has been laid down only after careful debate, it seems to me that if a professional seeks to serve the public interest and if what is in the public interest is best left to the public to determine, the doctor's brief does not extend to violating whatever constraint is composed. This is an invitation to disaster. It is of course open to the doctor to decide he wants no part of such a system and to withdraw, as for example, those who seek to escape the NHS for private enterprise medicine have done, but this is a wholly different decision.

I agree completely with Thomas that the public should 'provide a moral framework ... within which doctors make the clinical decision'. This has always been my position; that discretion must inevitably be left to the professional but that it should not be unfettered. The words 'clinical decision' however cannot stand unanalysed. For there is the danger that Thomas's position allows for the doctor alone to define the ambit of what is a clinical decision and by so doing define out of the proper scope of public comment decisions which ought to be within it.

Thomas's final paragraph is disappointing. After the open-mindedness of the rest, the doors suddenly slam shut. Better training in medical ethics is occurring at present, informed consent has been widely introduced, and consumerism and stricter discipline are uncalled for. Once the big issues have been settled, trust the doctor. Once again Thomas uses language such as 'major moral issues' to define away the public's right to comment. Which issues are major and who decides? Why should minor moral issues if they exist be for the doctor alone to decide? This is the important part of Thomas's paper, against which all else must be judged. I dispute all his assertions and regret his conclusion. It reeks of complacency, a complacency which is not justified by much of the limited evidence which exists. It is part of a strategy, give a little but nothing which counts. Such a strategy arises from a mentality of feeling embattled, feeling a need to defend territory under attack. This mentality will get us nowhere. Only when those who claim to speak for doctors realise that there is much that can aid and assist them in the notion of ethical guidelines, accountability and consumerism will a more productive dialogue be possible.

\section{Schamroth}

I thought I made it more than clear that I regarded much of the state of modern medicine and attitudes to health care to be a product of social and political forces rather than the particular doings of doctors. Indeed I sought to stress this time and again. I find the work of Draper's unit at Guy's Hospital, London most instructive (7). For example, I pointed to the relationship between unemployment and ill-health, to the false economy of social policies which pile up health problems for the future, and to the anti-health forces of the tobacco and food industries. I suggested that to achieve the goals of better health I had in mind, most profound social changes were required. Schamroth chooses not to notice this when he attributes to me the view that only doctors stand between a disease-oriented service and the desired health-oriented service. Nowhere do I advance this view and Schamroth's failure to notice a central thread of my argument is at least disappointing. Take for example the paragraph in which it is alleged that I blame doctors for the creation of an inappropriate form of medicine and in so doing I camouflage 'the real and more telling relationship between economics and health'. I would make two comments. First, I specifically argue that doctors are not alone in shaping the image of modern medicine. Second, I draw the distinction, which Schamroth does not, between medicine as an institution which has at best a limited effect on health widely defined, and the quite separate issue of the pursuit of health. The latter I point out turns on economic and social policies which are for government and are outside the power of doctors to affect one way or another. Surprisingly Schamroth later in his paper allows that I make this crucial distinction; 'general health has little to do with medicine'. But unembarrassed by the fact that his criticism may be looking both ways at the same time, Schamroth trumps me by attributing to me the view that health services 
should be able to redress the social and political causes of ill-health. This of course is not my argument, which can be stated in two short propositions. To the extent that medicine can improve health, the present organisation of medicine militates against this end. To a large extent health is a product of social and economic organisation: such organisation at present is not compatible with the achievement of health, far less, the improvement of health for society as a whole.

Schamroth's comments on his own experiences as a student are most valuable. They put into relief the views of those, often removed from the realities of medical education, who point complacently to the ethical training medical students receive. $\mathrm{He}$ is right to sound aggrieved at the present state of affairs. In a sense he is an innocent party to the perpetuation of the unsatisfactory state of affairs he exposes. He is a leading member of the London Medical Group, one of the Groups which have rapidly spread all over the UK. Admirable as they are, such groups may well be a Trojan Horse. Their existence allows the medical schools to avoid incorporating medical ethics into the curriculum in all but a perfunctory matter. The Medical Groups will take care of it. But who attends the meetings of the Groups ? Largely those who are already interested in ethics and anxious to learn more. The rest, probably a majority of students do not attend. Arguably it is these who need the education, yet they can and do avoid it.

\section{Carson}

Time will judge whether Carson's view is right that the lectures will fail to accomplish their stated purpose of broadening the debate about medicine. So far it may be that Carson is right, since much energy has been spent merely on dismissing them. I am not persuaded, however, that Carson's reasons for such a failure, if it be so, are valid. Indeed at the outset he joins the ranks of those who prefer argument by epithet to argument by reason when he questions my appeal to 'pallid utilitarianism.' What does the word pallid add, save to suggest that Carson does not like utilitarianism ? One is entitled to something more by way of argument. Next I am 'politically naive' to suggest that GPs can achieve much because of their relative powerlessness. I happen to think Carson is wrong and that the GP is gaining power and authority. The recent report of Dr Brian Jarman on the health care of Inner London is an example of the willingness of the Royal College of General Practitioners to flex its political muscle. Then, I 'weakly acknowledge' some merit in arguments for freedom of the individual but brush them aside. Carson may not realise that the constraints imposed by the form of the lectures prevented me from chasing down each and every philosophical argument. I make no claim to have exhausted the issue of individual freedom. I do suggest that Carson could find an issue for debate indeed he did and that was my purpose. And could find an argument for ignoring the claim to individual liberty in the context of wearing safe t, belts when the consequence of the exercise of that liberty is a charge on the public purse. He may ngt accept the argument. He may be infatuated with the US tradition of fundamental rights which has real parallel in the UK. The epithet 'weakly' the्f can be understood as a substitute for the propositiớn that Carson does not agree.

Carson then moves on to 'moderate disagreement" particularly in relation to my views on ethics. $\mathrm{f}_{3}$ suggests that ambivalence in making moral judg ments is a 'subtle acknowledgement by doctors of their uneasiness in making moral judgments and to be welcomed'. If a consequence of such unease had been the realisation that guidance in ethica decision-making from society at large was called for, I too would welcome it. But if such unease exists, it has not expressed itself so. Instead, many doctors particularly those who see themselves as the spokesmen for the profession have particularly their comments since the lectures rejected either th existence of a moral component, or if they have conceded its existence, have insisted that it was f\& doctors alone to determine. Thus I beg to differ with Carson.

His next disagreement makes me despair. agrees with my view that the humanities shoule receive greater emphasis in medical education, and then criticises me because I 'seem to mean b humanities chiefly ethics'. This is most irritating Had I meant ethics I would have said so. I specif5 cally chose the word humanities because I had in mind such disciplines as philosophy, history and se. on, which Carson thinks such a splendid idea! O the matter of who should teach medical ethics, Carson and I may differ only in terminology. Mg 'outsider' is probably the same as his 'resident alien? and I find his term attractive. To be such a residen alien, however, would mean appointing to the medical school staff someone other than a doctor of medical scientist. This is what I would like to sees but I doubt it will happen. Until it does it may have. to be an outsider.

Finally we have Carson's recital of my major shortcomings. The first is my treatment of the rhetoric of medicine. I confess I find Carson's comments hard to follow here. It would follow from my proposition that illness is a status termo conferred by doctors (that it has become a technicas term), that I would be concerned with the process ${ }^{5}$ whereby it was applied. My analysis has it that the patient is the claimant for the status, and tha? the doctor is the one to satisfy or deny the claim. " phenomenological analysis of the experience of illness' though interesting in itself, is not immedie ately relevant to this argument. I take Carson's poin $\$$ that I am concerned to redress the imbalance of 
power in the doctor/patient relationship. It does not necessarily follow, as he suggests it does, that the status ill be redefined to take account of patients' perceptions of illness. Rather, my point is, first, that there is a moral or evaluative component in the notion of illness, which Carson accepts, and second that the moral principles which should be referred to should be those of society at large (not necessarily those of patients).

The second shortcoming is my treatment of consumerism. Carson considers it 'intemperate' and 'gratuitously provocative'. For what it is worth, I suggest a greater familiarity with the realities of medical practice in the UK might persuade Carson otherwise, a point echoed in both Ackroyd's and Little's papers. It is quite simply true that the BMA which claims to speak for doctors was and is hostile and intransigent in the matters I referred to. When he refers to informed consent, Carson has it that I am in error when I say that it is a product wholly of the courts. This is a bad point. Greater attention to what I said would have allowed Carson to see that I was talking about law and contrasting court-made law with legislation. In the context, informed consent is a doctrine created by the courts. This is not to deny, nor would I be as silly as to argue otherwise, that it is also a central ethical concept. But in the context, I was concerned with litigation. As for what he would have liked me to say about informed consent, that it cultivates an exchange of information and permission, and so on, if he looks he will find that I made precisely this point.

Carson's final flourish is unfortunate. I set myself the task of unmasking. I sought to explain why. If Carson wants to decide that I attempted (and ultimately failed to accomplish) a demythologising of medicine that is his business. It is not what I claimed nor on what I sought to be judged.

\section{Clare}

I find Clare's paper particularly disappointing. I suppose it supplements Wilkes' paper as a glossary of the points of condemnation which have appeared elsewhere, particularly from psychiatrists, eg Roth (8) and Storr (9).

Clare begins with the now rather boring and irrelevant reference to the fact that I am by training, a lawyer, nudge, nudge, wink, wink! Then, doctors have been saying what Kennedy said for years. This is a spectacular indictment of doctors (all doctors? Dr Clare? or which ?) if Clare is to be believed that my views are hopeless. The purpose of course is to suggest my lack of originality. Clare even alleges that $I$ have never claimed that my arguments were original, 'nor indeed need he'. I have never said any such thing. I do not feel it necessary to argue the point here. I am happy to leave it to others, see, eg Black supra. Clare even takes me to task for not acknowledging the fact that doctors have been saying what I said for years (sic). I would have thought Clare's experience of broadcasting would have taught him that the nicer points of footnoting and acknowledging sources are inappropriate in lectures designed for the audience I was addressing. For instance, suppose I had said, 'As McKeown has argued', I would then have had to explain who McKeown is and why we should pay attention to his views. That would take about 30 to 40 seconds in a lecture of 29 minutes ro seconds. Six such references would take ten percent of my lecture! In my book I give full acknowledgement of every source; I even include Clare's book in the Bibliography! Such points as these within the first few lines of a critical paper set a rather peevish tone and tend to say more about the person writing them than the writer under review.

There follows what purports to be a recital of my arguments but which seems at best a paraphrase of what I said in the second of the six lectures. Clare's first substantive point is, I suggest, illconceived. I agree that it is conceivable to think in terms of a cure for, eg the common cold. But this was not my point. I was merely saying that there are now no cures for colds and the other ailments listed. I was suggesting that despite this, medicine is conceived of in terms of cures, and that this is inappropriate in that, among other things, it creates a climate of false expectations. Further, I argued that the intellectual and conceptual baggage accompanying the word disease plays an important part in this misconception of the role of medicine.

Clare's next point is most interesting and important. I am a 'Cartesian dualist', he says, 'since my notions of psychological disturbance appear to rest on an assumption that all such disturbance is social.' In fact I made no assumption that 'all such disturbance is social'. I merely chose to illustrate my argument concerning the evaluative and socially determined nature of illness by my example of Mrs Jones. Nowhere in my six lectures Clare argues do I consider 'the question of the genuinely medical "mental" problem'. What a delicious pre-emptive strike this is. By using the word 'genuinely' Clare of course assumes what has to be proved. If we take the example offered by Clare of a different Mrs Jones, just home after delivering her second baby and entertaining views profoundly out of character, I would suggest that despite what Clare says, I do consider such a case. I would suggest that in my fifth lecture I provide for the option of categorising as mentally ill those who seek help, it having been recognised by them or others that help is called for. Clare's Mrs Jones falls into this category and if she seeks help from those who practise in the field of mental health, I distinctly said that it was open to those from whom she sought help to regard her as ill and indeed mentally ill. 
Next Clare moves on to consider in detail what is of particular interest to him as a psychiatrist, my comments on mental illness. I confess that in the opening remarks in this section of his paper, Clare so completely misstates my view as to make comment difficult. I do not concede status to the notion of mental disease (a term I do not use) in relation to two elements, dangerousness and sympathy. Nor do I argue that the issue of mental disorder (a term I do not use) is raised when behaviour goes beyond what we are prepared to tolerate or when it evokes sympathy. I refer to intolerable behaviour or the evocation of sympathy as being the second stage in the present process of categorising someone as mentally ill, the first stage being the need for the judgment that the person's mentation or behaviour is abnormal. Of course, Clare is right that 'many behaviours go beyond what is tolerable' or 'evoke sympathy', without raising any question of mental illness. But he has ignored the other part, the first stage, of my argument. This is just not good enough in one who would criticise. It certainly does not warrant Clare's next sentence, 'this confusion is exacerbated', since the confusion is Clare's not mine. My views are not perhaps conventional nor are they necessarily sound since I am seeking to unravel what is very complex. But they deserve to be criticised for what they are, not for some mishmash of them.

What of Clare's comments on my suggested categories of mental illness. His first witness against me is the manic, which we are assured is hardly a bogus disease, but 'a readily recognisable clinical syndrome'. Here again we meet the pre-emptive strike and a refusal to respond to my arguments concerning the necessarily and exclusively evaluative nature of such a category. There are 'identifiable signs of psychological dysfunction' says Clare, and there's an end to it. Any more penetrating analysis is unwarranted. The thrust of Clare's criticism is that my categories of mental illness would not include the manic and therefore by implication the manic would go without care. The criticism is unwarranted on both grounds. First, how does Clare get to see the manic. Is it not because at some point he comes to see his doctor, or his friends or relatives urge or persuade him to do so? Does this not bring him squarely within my second category, the person who seeks help? Second, care and support are not uniquely within the gift of those who concern themselves as professionals with mental illness. A principal concern of mine is that by medicalising our response to certain behaviour we have persuaded ourselves that care is a matter of expertise which we non-professionals cannot give, so that with a clear conscience we can wash our hands of the need to care. This, I suggest, is to be regretted.

Clare's second witness is the dissident, a word which is undefined. Clare would have it that according to my categories of mental illness, dissident is mentally ill. Again, I regret, Clare make no obvious attempt to concern himself with whit I argue. If by the political dissident Clare meass someone who entertains dangerous or threatening ideas, such a person would not qualify under ne criteria, although, as I suggest, he may well do 59 if existing approaches to mental illness are adopte Indeed, dangerousness is at present used as a reason for refusing to release prisoners from prison or special hospitals and such dangerousness is left $\underline{\underline{\theta}}$ the assessment of psychiatrists. I demanded not mere dangerousness but dangerous conduct whie日 violated the law. If Clare's dissident engaged such conduct, I went on specifically to provide for and insist upon the separation of the criminal from the mentally ill. This judgment I suggested was for tribunal of lay people to decide, and in essence is a judgment about responsibility. If the dissidemt were adjudged responsible then his dangerous conduct would be treated as criminal. Thus Clares strictures on my failure to distinguish between tife criminal and the mentally ill are simply unwa를 ranted.

Clare ends as he began with another swipe at m lack of originality, then he rallies, the faithfeg arguing that psychiatrists 'have to argue their case painstakingly and stubbornly'. Stubborness does not strike me as a particular virtue in argumen As for being painstaking, I could have wished th Clare had followed his own advice.

\section{Bamford}

I am invited to comment on the case presente] briefly by Bamford.

I) Bamford begins by offering a paraphrase of $\mathrm{mH}$ views on autonomy which regrettably contains none of the suggestion of partnership in decisior making between doctor and patient which in fagt I urged was crucial. This is unfortunate. Bamfor is immediately trapped in an analysis in which decision-making must rest with one party or another; in which responsibility cannot be share Such an analysis tempts him to conclude that the case serves 'to question the appropriateness of leaving difficult decisions to patients rather than to their doctors'. In other words, he would see the case as illustrating the doctrine that the doctót knows best when 'difficult decisions' are called for 2) No analysis is offered of what a 'difficult' decisiog is, warranting paternalistic action by the docto I would suggest Bamford would find it hard to produce rationally defensible criteria of difficult He may say that difficulty is a question of factua complexity. But first, this is not borne out by the facts of his case. Second, factual complexity cannot alone serve as a criterion for denying patient participation in decision making. The docto owes the competent patient the duty to commun 
cate all relevant facts in a comprehensible form. Failure to do so denies the patient the power to make a considered judgment which can then be discussed. Alternatively, Bamford may mean by difficulty, ethical complexity. But there is no suggestion that this is what he means nor is there generally any reason to believe that the doctor is possessed of greater powers of ethical analysis, qua doctor, such that as a matter of general policy he should decide such problems.

3) Bamford insists that the case is one in which 'decisions made by the patient and supported by her doctors were found to be consistently inappropriate to her changing lifestyle'. It is not clear what Bamford wants me to make of this. First, no professional nor layman guarantees that he will always be right, nor is this expected of him. Second, professionals and laymen make judgments in the light of known facts and reasonably foreseeable future events. Circumstances may render such judgments regrettable but this may not mean that they were wrong or inappropriate at the time. Thus for Bamford to suggest that the decisions taken were later seen to be inappropriate does not mean that they were bad decisions at the time they were taken, all things considered. Indeed, Bamford's use of the word inappropriate may beg the question since it seems that at all stages Mrs A C's decisions were approved of or at least supported by those advising or helping her, and to that extent they were appropriate. Only with hindsight were they deemed inappropriate. Bamford hints that 'the outcome (which?) might possibly have been predicted'. No evidence is offered to explain this. If some degree of prediction had been possible then it may be doubtful whether Mrs A C would have chosen the particular path she did choose. But, even assuming she would have, the responsibility of the doctor, as I suggest later, would have been to explore such predictions with the patient and perhaps if he felt it were justified, to refuse her various requests. Finally, Bamford does not explain how, on the facts, the relevant doctor would have made more appropriate decisions (however defined). 4) As regards the particular facts of the case, it is fair to say that it concerns various types of medical intervention which call for especially careful ethical analysis. The case involves a series of requests made by a healthy woman for surgery to satisfy social needs. This is not the norm of medical treatment. A healthy person is making a request of a doctor. The limit of the exercise of autonomy here is to make the request. There is nothing in the notion of patient autonomy or partnership in decision-making which says that every such request should inevitably be granted. Arguably requests should be gratified if, after full exploration of the circumstances, the person requesting and the doctor feel that the intervention is justified, both on the facts and in ethical terms. If the doctor is not so persuaded he can legitimately refuse to grant the request. For, in the context of surgery for social reasons, the doctor's duty extends only to stating the relevant facts and thereafter good medical ethics would suggest there are circumstances in which he may refuse to act further. This is in contrast to the norm of medical treatment in which good medical ethics would ordinarily demand that the doctor take some action to treat the ill who wish to be treated.

Thus the case of Mrs A C calls for precisely that form of partnership between doctor and patient which I suggested is the key to good medical practice. Indeed, on the facts this is what occurred. That events chose to take a curious course should not alter our confidence in this principle.

\section{References}

(I) Kennedy I. The Unmasking of Medicine. Allen \& Unwin, 198r.

(2) Watkins J F. Review of The Unmasking of Medicine, Times Literary Supplement I98I June 26.

(3) Illich I. Limits to Medicine. Harmondsworth: Penguin Books, 1977.

(4) Cartwright A, Anderson R. Patients and their Doctors 1977, Institute for Social Studies in Medical Care, Royal College of General Practitioners Occasional Paper 8, 1979 March.

(5) Inequalities in health. (The Black Report). London: DHSS, 1980.

(6) Kennedy I. In the public interest - the accountability of professionals. BBC Radio. I98I June ro.

(7) The NHS in the next 30 years: a new perspective on the health of the British. Unit for the Study of Health Policy, Department of Community Medicine. London: Guy's Hospital Medical School.

(8) Roth Sir Martin. Reflections on the Reith Lectures. Cambridge Review I98I March.

(9) Storr A. Review of The Unmasking of Medicine. The Sunday Times 1981 Aug 30. 